\section{Cost to the NHS of accidents to children in the West Midlands}

Accidents consume about $1 \%$ of a developed country's gross national product $(£ 2500 \mathrm{~m}$ for the United Kingdom in 1984; Royal Society for Prevention of Accidents, personal communication). This estimate is vague and includes notional valuations for grief, suffering, and loss of earnings. Published data on the specific health costs of accidents in childhood are limited.

\section{Methods and results}

Data on specific classes of accident and on outpatients were obtained from the Department of Trade's home accident surveillance system. Details of inpatients in the West Midlands were obtained from Hospital Activity Analysis. Details on treatment provided by general practitioners for children injured in accidents were taken from morbidity statistics for general practice. ${ }^{1}$ An incidence of permanent disability (18.6/100000 accidents) and a breakdown of types of disability expected were provided by a report on long term disability after accidents in childhood. $^{2}$

Inpatient treatment (with hotel components), outpatient treatment, and

\section{Comment}

The short term care of children injured in accidents consumed $£ 9 \cdot 2$ million of health service resources ( $£ 9$ per resident child). Accidents in the home were the most expensive because of their great number. Burns (in preschool children) and pedestrian accidents (for older children) had both high short term costs and a high rate of disability. The long term medical costs of accidents that result in permanent disability could not be fully identified because when patients were readmitted they were classed according to treatment specialty (for example, burns were classed as plastic surgery and paraplegia as orthopaedic surgery). Costing confirms the humanitarian response that preventive action should be concentrated on these disabling accidents because their costs are both high and recurrent.

Potential savings may be overestimated, in particular savings on patients admitted overnight for observation. The potential for lower admission rates is questionable as medicolegal constraints operate. About $30 \%$ of the total costs of accidents remains unclassified indicating uncertainty in classification and coding. ${ }^{4}$

Most children hurt in accidents were previously fit and healthy. Accidents in childhood now constitute an epidemic similar in magnitude to the epidemic of infectious diseases in Victorian times. A similar public health approach is needed to prevent them. Action, not assent, should be given to the aphorism that prevention is better than cure.

Number of children treated after accidents, and costs, in West Midlands, 1984

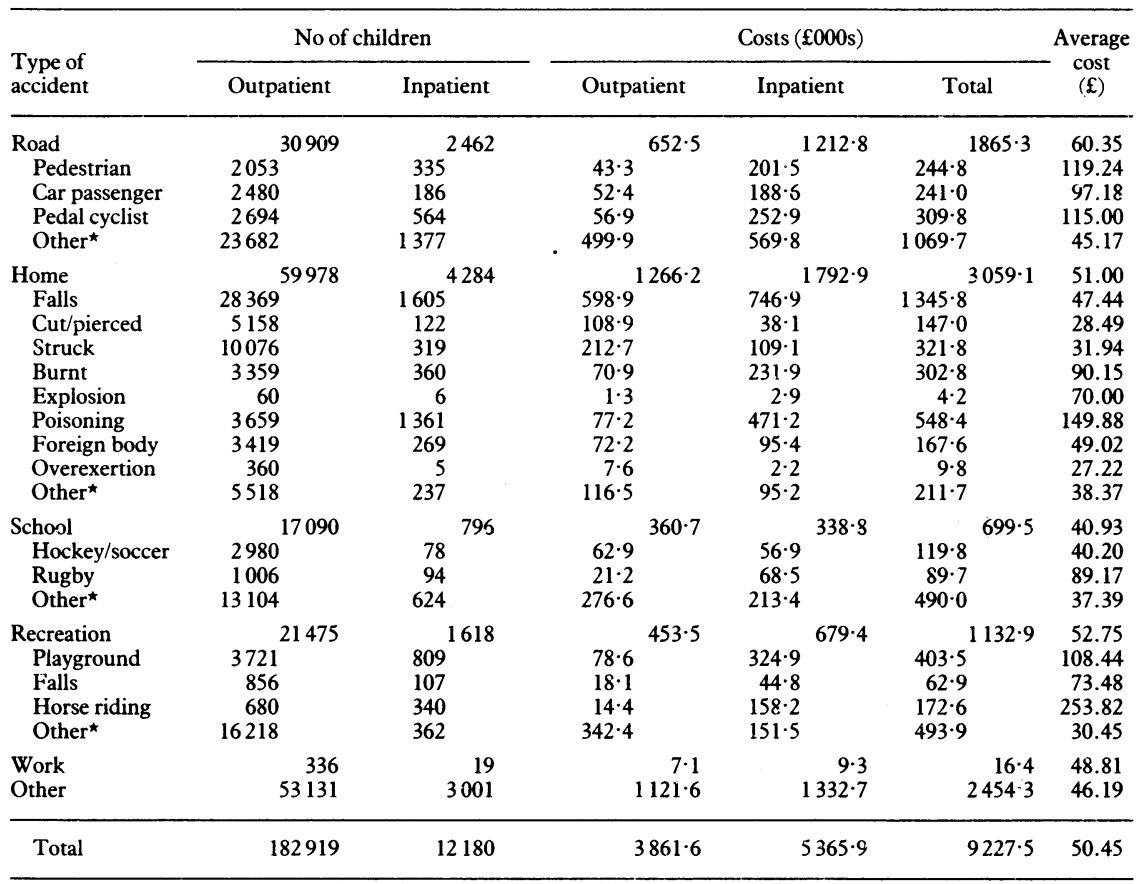

${ }^{\star}$ No further details avaiiable.

treatment by general practitioners were costed in general terms; more specific calculations were made for accidents resulting in permanent disability. All inpatients were assumed to visit outpatient departments at least once. Outpatient treatment was costed from the West Midlands Regional Health Authority's costing returns; care by general practitioners was costed from an abstract of statistics, which also provided prescription costs. ${ }^{3}$ Information on costs of treating burns in children suffering from permanent disability was obtained from the Medical Research Council's industrial and burns unit at Birmingham Accident Hospital. Based on the limited data on general practitioners' treatment of people injured in accidents, the total cost was estimated at between $£ 570000$ and $£ 810000$.

In $1984,17 \cdot 6 \%$ of children in the West Midlands sought treatment after an accident. This consumed $£ 9 \cdot 2$ million of National Health Service resources (table). Accidents in the home were the most expensive, constituting one third of the total costs. Road traffic accidents, although accounting for only $9 \cdot 3 \%$ of the total costs, had the highest average cost $(£ 108 \cdot 48)$, which was twice that of accidents in the home $(£ 51 \cdot 00)$. The average cost reflects both inpatient and outpatient care and hence varies directly with admission rate. This is evident in road traffic accidents, poisoning, and horse riding accidents (admission rates of $14 \cdot 7 \%, 37 \cdot 2 \%$, and $50 \cdot 0 \%$, respectively).

There were some uncertainties in costing practices, and we assumed that all casualties were treated in a paediatric ward. The cost of treatment in a more appropriate specialty would be more realistic-for example, the cost of treating severe burns by plastic surgery ( $£ 2800-7700)$ is considerably higher than the average cost of paediatric care (£644).
We are grateful to Dr Mike Drummond, Health Services Management Centre; Mr Harry Ward, Central Birmingham Health Authority; Mrs Judith Baker, Department of Trade and Industry; and Dr J C Lawrence, Birmingham Accident Hospital, for much time spent in discussion. This work was funded by the Accident Prevention Action Group of the West Midlands Regional Health Authority.

1 Department of Health and Social Security. Morbidity statistics from general practice, second national survey, 1970-71. London: HMSO, 1974.

2 Avery JG, Gibbs B. Long term disability following accidents in childhood. In: Proceedings of the symposium on accidents in childhood. London: Child Accident Prevention Trust, 1985:27-39. (Occasional paper No 7 .)

3 Central Statistical Office. Annual abstract of statistics. London: HMSO, 1986.

4 Sunderland R. Inaccurate coding corrupts medical information. Arch Dis Child 1985;60:593-4.

(Accepted 29 October 1987)

Children's Programme, Springfields, Raddlebarn Road, Birmingham B29 6JD

V VIPULENDRAN, MB, MRCP, paediatric registrar

A R MASON, BA, MA, health economist

R SUNDERLAND, MD, MRCP, consultant paediatrician

Correspondence to: Dr Sunderland 